\title{
Relinquishing Control: What Romanian De Se Attitude Reports Teach Us About Immunity To Error Through Misidentification
}

This is the penultimate draft. Forthcoming in Alessandro Capone, Manuel Garcia-Carpintero, and Alessandra Falzone (eds.), Indirect Reports and Pragmatics in the World Languages. Springer International Publishing. (2018)

\begin{abstract}
Higginbotham (2003) argued that certain linguistic items of English, when used in indirect discourse, necessarily trigger first-personal interpretations. They are: the emphatic reflexive pronoun and the controlled understood subject, represented as PRO. PRO is special, in this respect, due to its imposing obligatory control effects between the main clause and its subordinates (Chierchia (1989)). Folescu \& Higginbotham (2012), in addition, argued that in Romanian, a language whose grammar doesn't assign a prominent role to PRO (if it assigns it a role at all), de se triggers are correlated with the subjunctive mood of certain verbs. That paper, however, didn't account for the grammatical diversity of the reports that display immunity to error through misidentification (IEM henceforth) in Romanian: some of these reports are expressed by using de se triggers; others are not. Their IEM, moreover, is not systematically lexically controlled by the verbs, via their theta-roles; it is, rather, determined by the meaning of the verbs in question. Given the data from Romanian, I will argue, the phenomenon of IEM cannot be fully explained starting either from the syntactical or the lexical structure of a language.
\end{abstract}

\section{Introduction}

Higginbotham (2003) starts from the observation that certain linguistic items, in English, necessarily trigger first-personal interpretations. The particular linguistic items are the emphatic reflexive pronoun and the controlled understood subject, represented as PRO, used in attitude reports in the indirect discourse mode. ${ }^{1}$ Chomsky (1981) argued that, although controlled PRO doesn't have a

\footnotetext{
${ }^{1}$ I use "indirect discourse" with the same meaning as Cumming \& Sharvit (2016: 489): "the matrix clause in "Whenever Alice begins a game of chess, she expects PRO to win" is an attitude report in the indirect discourse mode." All the examples discussed in the current paper have the same structure.
} 
phonetic realization, it has an interpretation: it is necessarily anaphoric to the main clause subject. The interpretations these items are seen as triggering are the so-called de se readings of certain sentences. Higginbotham assumes that there is something particularly de se in the relevant cases that cannot be cashed out as either de re or de dicto readings. He argues that in English, contrary to what one may expect, this de se element is always connected to PRO, in the sentences where it appears, and only sometimes with the emphatic reflexive pronouns. This feature of PRO is exploited by Higginbotham with the following result: even in some cases where PRO doesn't seem to make any appearance, like the ones where someone says (or thinks) "I am pained", it is the fact that there can be no split reference between the subject that thinks "the subject of that state (i.e. being in pain) is being pained" and the subject that undergoes the feeling of pain that is responsible for that report having immunity to error through misidentification (IEM henceforth) ${ }^{2}$ In such cases, there seems to be a sort of mental PRO that ensures that it is nonsensical to ask who is being pained.

Higginbotham (2003) argues that there is a very strong connection between de se, IEM and PRO. This connection is supposed to be the following: whenever we have a report where PRO is present, that report is de se; whenever we have a report that is de se, that report will have IEM; and, moreover, whenever we have a PRO context, that context is guaranteed to have IEM. To be precise, this is not to say that non-PRO contexts cannot be de se or, equivalently, that a de se attitude report is never triggered by other items. Higginbotham's claim is that PRO always signals a de se report. This is because a de se report (or, equivalently, a report that has IEM) presents the subject as the experiencer of the state the report is about and Higginbotham's observation is that the semantic contribution of PRO is to always present "the subject as the experiencer of the event or state $e$ as given in the higher clause."3

These are all very general claims, especially since the main argument is based on the syntactical

\footnotetext{
${ }^{2}$ Beginning with the work of Wittgenstein and Shoemaker, it has been commonly held that certain reports of experience are such that it makes no sense for one to wonder whether it is oneself that is having that experience. For instance, if one says "I am pained", it is nonsensical for that person to ask the following question: "I know it is pain that is being felt, but is it $I$ who is feeling this pain?" Higginbotham (2003: 507) argues that a report (or a thought) like "I am pained" has IEM because, whenever I am in that painful state, my thought is of the form "the subject of that state is being pained." The question of identifying myself with the subject of the state doesn't even arise in such cases.

${ }^{3}$ Higginbotham (2003): 514.
} 
structure of only one natural language: English. To argue that the very nature of thought, in general, is determined by how a particular language is structured may seem too bold, even if we subscribe to the controversial Sapir-Whorf hypothesis, broadly understood to mean that language doesn't just give us a way to express our thoughts, but, rather, that it determines the formation of those very thoughts. However, a more modest idea, that certain thoughts display IEM and that thoughts like those are systematically expressed in certain ways in different languages is worthy of further consideration. Folescu \& Higginbotham (2012) investigated whether data from other languages, in particular Romanian, support a thesis like this. According to Folescu \& Higginbotham (2012), in Romanian, PRO does not play the syntactical role it does in English; however, the data discussed suggests that Romanian may have obligatory control elements akin to PRO, which force a de se interpretation of the relevant reports, and thus support the idea that those reports have IEM. The subjunctive mood of certain verbs was found to be (weakly) correlated with de se triggers and, thus, introduction of reports that have IEM.

Folescu \& Higginbotham (2012), however, didn't take into account the grammatical diversity of the reports that display IEM in Romanian: some of these reports are expressed by using de se triggers; others are not. Moreover, in this paper I will argue that in Romanian, there are reports that syntactically do not look as if they're expressing de se attitudes (since they do not use any de se triggers) that are, nonetheless, expressing thoughts with IEM. Their IEM, moreover, is not systematically lexically controlled by the verbs, via their theta-roles; it is, rather, determined by the meaning of the verbs in question. Given these more complete data from Romanian, I will argue, the phenomenon of IEM cannot be fully explained starting either from the syntactical or the lexical structure of a language. This shows that maybe we should think that a certain context having IEM is determined by that context being about the right kind of psychological state. I will thus suggest that psychology rather than language may be the key to understanding the phenomenon of immunity to error through misidentification. ${ }^{4}$ Capone (2016: 253) seems to make a similar point, when he writes that "the first-personal dimension of PRO in constructions like 'John remembers walking

\footnotetext{
${ }^{4}$ This is building on the thesis developed in Recanati (2007: 145-47), according to whom IEM belongs to reports about mental states with the right kind of mode - i.e. perceptual mode, or memory mode, etc.
} 
in Oxford' should be further characterised by making use of a mode of presentation like 'I'.' It may be unclear, without further work, what exactly makes a state be of the right psychological kind, or what exactly is an I-mode of presentation. Such work will not be done in this paper, which is occupied with understanding how far language can take us in deciphering whether the psychological state in question is of the right kind.

To begin, in $\S 2$, I briefly review Higginbotham's claims about the connection between IEM, de se, and PRO. In $\S 3$, I talk about the Romanian counterparts of the relevant examples used by Higginbotham, showing why their syntax is importantly different and why there is no room for PRO in their grammar. These examples are relevant, because they constitute clear cases of IEM, even though their IEM character can't be pinned down on anything in their syntax.

In $\S 4$, I will investigate whether there may be something else, not in the syntax, but in the lexical features of the relevant verbs, that determines whether the reports they belong to have IEM or not. Can a different type of obligatory control have the same effect in Romanian as PRO has in English? To answer this question, I will discuss several examples of verbs whose lexical properties impose obligatory control and contrast these with verbs that do not have lexical control effects on the subjects of subordinates. The upshot of this discussion will be that IEM is not, in effect, connected with this type of obligatory lexical control, since IEM belongs, in equal measure, to sentences using the first and second type of verbs. The IEM/no-IEM distinction, thus, is orthogonal to the lexical control/no-control properties of the relevant verbs. The conclusion of this investigation is that IEM cannot be gleaned only from the linguistic structure of a language, be that English or Romanian.

\section{The connection between IEM, de se, and PRO, in English}

According to Higginbotham (2003 \& 2010) there are two types of contexts that can and have been read as distinctly de se. We have, on the one hand, pronomial (reflexive) complements and, on the other, controlled complements. Compare, for instance, sentence (1) and (2), where the first has a 
pronominal complement, while the other has a controlled one, inside the scope of the attitude verb:

(1) George wants [him/himself to eat the hamburger.]

(2) George wants [PRO to eat the hamburger.]

Higginbotham (2010), p. 255 argues that the grounds warranting the assertion of sentence (1) are different from those warranting the assertion of sentence (2). To find out whether George of sentence (1) has that particular desire, one will probably use an inferential process based on an identification between the subject of the embedded sentence with the referent of a certain definite description. Here's a scenario supposed to make this idea vivid: suppose that George is part of a group of hungry people but he, being the selfless character that he is, wants that the hungriest member of the group eat the only available hamburger. If it turns out that George is the hungriest member of the group, George will correctly be said to have the desire that he himself eat the hamburger. Only after George is identified as the hungriest member of the group, is the assertion of sentence (1) warranted. Sentence (1), thus, isn't (necessarily) a de se report: on this scenario, George may not realize that he is indeed the hungriest person in the group. If, on the other hand, one described the situation by using sentence (2), one will have communicated that George has the desire that the hamburger be his, no matter how hungry anyone else in the group may be. Higginbotham (2010) argues that this reading is forced by PRO: a context whose interpretation requires PRO is necessarily de se and always has IEM. In using (2), the speaker excludes the possibility that George doesn't realize that it is he himself who wants to eat the hamburger.

There are two types of PRO-contexts that Higginbotham considers: infinitival complements (like sentence (2) above) and gerundive complements, like sentence (3):

\section{(3) George imagined [PRO flying through space.]}

We can include explicit markers, like "himself", to replace the silent PRO in a sentence like (3), thus obtaining:

(4) George imagined [himself flying through space.] 
Doing so, however, changes not only the appearance of the initial sentence, but also its interpretation: sentence (4) could be understood to say that George imagined of himself that he was flying through space without realizing that he himself was the one flying. On the other hand, Higginbotham claims that sentence (3) cannot be interpreted in this way: it would be contradictory to say that George imagined flying through space, without realizing that it was he who was flying. According to Higginbotham, this proves that PRO, and not the reflexive pronoun, is always linked with de se and IEM.

This amounts to saying that, in some sense, PRO is more immune to error through misidentification than the reflexive pronoun; contexts containing PRO are clearly de se, while those constructed with the reflexive pronoun may not be so. In the next section, I will consider the Romanian counterparts of the examples discussed here, in order to show that, in Romanian, if these contexts have IEM, their IEM character is not correlated with PRO.

\section{Neither de se, nor IEM is connected to PRO, in Romanian}

In this section, I provide answers to two main questions, by offering a detailed discussion of several examples from Romanian, which are the counterparts of the examples discussed by Higginbotham (2010). ${ }^{5}$ First, what contexts, if any, can be said to be de se reports, in Romanian? Second, what is the syntax of the Romanian sentences corresponding to the English ones that have controlled complements inside the scope of attitude verbs? The answers to both of these questions will show that neither de se nor IEM is connected to PRO, in Romanian. Cross-linguistic data of this kind indicates that it is not that obvious that some sort of "mental PRO" can account for IEM across the board, no matter the type of expression used in a particular language.

\footnotetext{
${ }^{5}$ This section provides all the data mentioned, but not discussed, in Folescu \& Higginbotham (2012: 54-57). In this sense, the material discussed here is supplementary to the one discussed in the earlier paper.
} 


\subsection{The emphatic reflexive pronoun}

The emphatic reflexive pronoun is a first good candidate for indicating whether a certain report has a de se reading. Here is the translation of sentence (1), in Romanian:
George $_{i}$ vrea
[să mănânce chifteaua
el insuși $\left._{i}.\right]$
George $_{i}$ want-3SG [să eat-3SG hamburger-the he himself $_{i}$ ]
'George wants himself to eat the hamburger.'

Sentence (5) has the same interpretation as its English counterpart: it sometimes signals a de se context; other times its evaluation depends on an inferential process, as the discussion in $\S 2$ pointed out. In such cases, the de se reading does not apply. In addition, sentence (5), just like its English counterpart, is not showing IEM, since its evaluation sometimes requires that we explicitly identify George with the referent of a certain definite description (as explained in $\S 2$ ). The emphatic reflexive pronoun, then, in Romanian, behaves just like its English counterpart: it sometimes figures in contexts that have a de se reading, but the usage of this linguistic item does not give rise to contexts that are intrinsically de se.

\subsection{Subjunctive subordinate clauses}

The next possibility is to see whether infinitival and gerundive complements of the relevant kind have an understood subject, of type PRO, in Romanian, just like in English, since PRO, in such cases, is the alleged bearer of IEM and forces a de se interpretation, according to Higgibotham. Or, even if PRO were not part of their syntax, their IEM, if they had it, could still be intrinsically linked to their syntax. In what follows, I investigate this possibility.

The first thing to notice is that, in Romanian, the subordinate clause, in the contexts of interest, is (usually) a subjunctive clause, and not an infinitival one, as it is in English. ${ }^{6}$ This is a feature common to Balkan languages: their historical evolution has seen the gradual replacement of infinitival clauses by subjunctive ones. ${ }^{7}$ Whenever an infinitival complement is required in English,

\footnotetext{
${ }^{6}$ I say 'usually' because the infinitive is, in some very rare cases, accepted. However, when the infinitive is accepted, the subjunctive is also allowed. In all these cases, the subordinate (be it in infinitive or subjunctive) is lexically controlled by the main verb. See the discussion in Dobrovie-Sorin (1994: 91).

${ }^{7}$ Dobrovie-Sorin (1994: 112).
} 
a subjunctive clause should be expected in Romanian. Sentence (5) constitutes a first example of this phenomenon. We should note that, by contrast to its English counterpart, the subject of the subjunctive clause is expressed, in sentence (5).

A type of null subject is sometimes allowed in Romanian subjunctive clauses:

$$
\begin{aligned}
& \text { George }_{i} \text { vrea [să mănânce } \text { pro }_{i} \text { chifteaua.] } \\
& \text { George }_{i} \text { want-3SG [să eat-3SG } \text { pro }_{i} \text { hamburger-the.] }
\end{aligned}
$$

'George wants to eat the hamburger.'

This null subject is not PRO, however, because the verb used in the subordinate clause has AGR features. Dobrovie-Sorin instead argues that "by virtue of its being "identified" by the AGR features of the verb, the null subject of Romanian subjunctives is rather of type pro, comparable to the subjects of tensed sentences." ${ }^{\prime 8}$ Even if this hypothesis were incorrect and the null subject were not pro, neither is it PRO, given that we have AGR. ${ }^{9}$ So, if sentence (6) constitutes a de se context, its generation is structurally different from the way de se contexts are generated in English. Sentence (6), moreover, displays IEM features, due, primarily, to the use of an IEM verb (in the sense of Folescu \& Higginbotham (2012: 55).) To see that this is so one should simply ask whether one can assert (6) and also say that George doesn't realize that it is he himself the one supposed to eat the hamburger. For contrast, consider sentence (7), which is not acceptable in Romanian:

George $_{i}$ vrea $\quad$ [să mănânce pro ${ }_{i}$ chifteaua, dar nu-și $i_{i}$ dă seama
George $_{i}$ want-3SG [să eat-3SG pro ${ }_{i}$ hamburger-the, but not-și $i_{i}$-DAT realize-3SG
că el $l_{i}$ este cel care ar mânca-o].
that he $\mathrm{he}_{i}$ is who would eat-it].
'George wants to eat the hamburger, but doesn't realize it would be he himself eating it.'

Its unacceptability is determined by it being impossible, in (6), to have split reference between the subject of the main clause and that of the subordinate, because the person of the subordinate verb is the same as that of the main verb, in this case.

\footnotetext{
${ }^{8}$ Dobrovie-Sorin (1994: 114). This claim was disputed, in recent years, since it was arrived at in the so-called 'pre-minimalist era.' However, the fact that the verb of the subordinate displays AGR should conclusively rule out the possibility of PRO, irrespective of the choice of framework.

${ }^{9}$ A question that will be addressed in the next section is whether we can talk about obligatory control between the main verb and the subordinate, given that the null subject isn't of type PRO.
} 
I conjecture that this type of subjunctive always behaves in this way in Romanian: split reference isn't allowed; so, when correctly formed, a subjunctive clause of this kind will always generate an IEM context. It remains to be seen what exactly is the syntactical feature that triggers the de se connection.

As indicated in Folescu \& Higginbotham (2012: 55), there are two types of subjunctive constructions, in Romanian: Subjunctive I and Subjunctive II. Subjunctive I, exemplified by (6), is used whenever the speaker wants to assert something about a particular person, who is taken to be the unique subject of both the main and the subordinate clause: no split reference (between the main subject and the subject of the subjunctive) can then arise. If, on the other hand, the speaker wants to highlight that the subject of the main clause is different from the subject of the subordinate, he will use Subjunctive II, as in (8):

George $_{i}$ vrea [ca el el $_{i / j}$ să mănânce chifteaua.]

George $_{i}$ want-3SG [ca he h $_{i / j}$ să eat-3SG hamburger-the.]

'George wants him/himself to eat the hamburger.'

It is customary, but not required, that, in a sentence like (8), the referent of the third-person pronoun in the subordinate be different from the referent of 'George' in the main clause. The context of utterance might, however, make it clear that 'George' and ' $\mathrm{l}$ ' have the same referent, even in a sentence like (8). The speaker might want to indicate that George thinks about himself as the satisfier of a description, rather than as the subject of the 'wanting-state', for instance, in which case the speaker would use sentence (8), where the pronoun in the subordinate gets its interpretation from the formative. But, upon hearing a sentence like (8), one would expect that the subject of the subordinate be different from the subject of the main clause. This, I argue, is a feature of Subjunctive II.

Since sentence (7) is unacceptable and since, usually, by employing Subjunctive II, one can say what (7) would say if it were acceptable, we should think that Subjunctive I is a trigger of de se in Romanian. Sentence (6) is a de se context: the embedded subject may not be anyone else than the main subject, and this is due to the construction being rendered in Subjunctive I. This shows that a 
de se context, which does have IEM, can be generated even in the absence of PRO. ${ }^{10}$

Folescu \& Higginbotham (2012) note this feature of Subjunctive I, without, however, noticing one of the most striking differences between English and Romanian, in cases like this. In English, infinitival contexts of the relevant kind always require a controlled null subject of type PRO in the subordinate. In Romanian, however, the embedded subject is not controlled in the same way. The syntactic structure of Subjunctive I does not require that the subject of the subordinate is the same as that of the main clause; it just allows it, if the circumstances are right. To see this, take, for instance, sentence (9), a good example of Subjunctive I, in which the subject of the subordinate is different from that of the main clause:

\footnotetext{
${ }^{10}$ Folescu \& Higginbotham (2012: 55) makes a similar point.
} 
(9) George $_{i}$ vrea [să mănânci pro $_{j}$ chifteaua.]

George $_{i}$ want-3SG [să eat-2SG pro $_{j}$ hamburger-the $]$

'George wants you to eat the hamburger.'

The subject of the English subordinate in (9) is an NP-trace, due to subject to object raising. The syntactic structure is visibly different from that of the English sentence, in (6) - where the subject of the subordinate is of type PRO. The same is not true for Romanian: there is no difference in structure between the Romanian sentence in (6) and the one in (9). The only difference is determined by the form of the embedded verb - in (6), it is in the third person, whereas in (9), it is in the second person. Thus, in Romanian, it doesn't seem plausible to argue that, on the one hand, in (6), we have a case of obligatory control, which binding theory, rather than PRO could explain, and, on the other, a case of NP-trace in (9) (where exactly is the subject of the subordinate raised?) ${ }^{11}$

These examples indicate that, whereas Subjunctive I could be thought to trigger de se contexts, whether those contexts also display the IEM phenomenon cannot be gleaned from the syntactical structure alone, in Romanian. IEM, thus, cannot be said to be connected with obligatory control (let alone with PRO), since the embedded subject, when Subjunctive I is used, is not necessarily controlled by the main verb. There is no way to know, by looking at the syntactical structure alone, that sentence (6) always expresses a de se context, while sentence (6) never does. At the level of syntax, sentence (6) is identical with sentence (9). ${ }^{12}$

\subsection{Gerundive subordinate clauses}

Gerundive complements, embedded under verbs like "imagine" or "remember" are the last class of examples thought by Higginbotham to support his conjecture that a certain type of (mental) obligatory control, rendered in English by the use of PRO, is the marker of IEM. As already pointed

\footnotetext{
${ }^{11}$ See Dobrovie-Sorin (1994: 114-118), for a discussion of the problem of control in Romanian. She suggests that control is sometimes allowed, but never necessitated, by certain syntactic structures, but she understands obligatory control as reducing to binding theory, since PRO is not an element belonging to the grammar of Romanian subjunctives.

${ }^{12}$ This contradicts the claim in Folescu \& Higginbotham (2012: 56). The data discussed there are inconclusive, as the examples discussed here indicate, especially the obvious syntactical uniformity of sentences (6) and (9), which is never mentioned in Folescu \& Higginbotham (2012).
} 
out in $\S 2$, in such cases, the subject of the subordinate clause is null and is of type PRO in English. Romanian, I will argue, is interestingly different here, too. PRO does not make an appearance in gerundive complements, either. The presence of IEM in such contexts seems determined by the verb used ("imagine", "remember"), rather than by the syntactic structure of a Romanian sentence. As a side note, PRO may be present in some contexts where the subordinate is a gerundive clause; however, such contexts do not have IEM features. In what follows, I discuss these phenomena in more detail.

\subsubsection{The Romanian null subject as NP-trace}

To begin, it is worth noting that both "remember" and "imagine" are so-called "reflexive verbs" in Romanian: they always include a reflexive pronoun, usually cliticized. While the pronoun associated with "remember" is always in the Dative, the one associated with "imagine" can, depending on the context, be either in the Dative or in the Accusative. Furthermore, one can have a gerundive complement inside the scope of "remember" or "imagine" only when the reflexive pronoun is in the Dative. In other words, only "imagine" can take a gerundive complement; the complements of "remember" are always expressed as 'that'-clauses. This already indicates that there are problems with Higginbotham's conjecture: the IEM of memory contexts cannot depend on either the gerund form or PRO, since there is no PRO in 'that'-clauses, in either English or Romanian, and using a 'that'-clause is the only way of generating a memory context in Romanian.

Let us analyze, however, what happens in cases of Romanian gerundive complements in the scope of the verb "imagine." The verb we are looking for is "a se imagina", where the "se" particle designates the Accusative form of the reflexive pronoun. Consider sentence (10) (which is the closest - meaning wise - Romanian sentence to sentence (3) above):

(10) George $_{i} \mathrm{se}_{i} \quad$ imaginează [zburând $t_{i}$ prin spațiu]. George $_{i} \quad s e_{i}$-ACC imagine-3SG [flying $t_{i}$ through space]

'George imagines himself flying through space.'

'George' is the subject of the main clause, while ' $s e$ ', the reflexive pronoun in Accusative, is the object of the clause, indicating that the act of imagination is about is George himself. The 
subordinate verb, 'zburând', takes the gerund form, which excludes any AGR features. What type of subject is the subordinate null subject, then: is it of type PRO or of a different kind? Since, in the subordinate, we have an instance of subject to object raising, we can confidently rule out PRO. NP-traces (marked as ' $t$ ', in sentence (10)), and in particular, the traces of raised subjects are considered to behave like anaphors, and are thus different from control structures (of which PRO is but one example). ${ }^{13}$ Sentence (10), therefore, is not displaying the usual control features that its English counterpart, where the subordinate null subject is of type PRO, does.

Sentence (10), however, seems to have IEM, since it is rather silly to ask whether the agent that imagines flying through space can be mistaken with regards to who exactly is flying. I do not believe that this is the result of there being an anaphoric relation between the NP-trace, that is the subject of the subordinate, and the object of the main sentence. Rather, I would think that the IEM features of sentence (10) are determined by the fact that (14) talks about an act of imagination. So, here we have an example of a context that exhibits IEM features, without it being a PRO-context.

\subsubsection{The Romanian null subject as PRO}

Let us now consider some alleged counterexamples: some Romanian gerundive complements, of the relevant kind, have null subjects which are obviously not NP-traces. Moreover, in such cases, some type of anaphoric binding, which may indicate that the null subject is of type PRO, seems to be at play. Let us assume that in such cases, PRO is part of the Romanian syntax. If, in addition, one could show that only these contexts display IEM features and are de se, Higginbotham's conjecture would be vindicated.

I believe, however, that such contexts display no IEM features. Consider the following:

George a
George have-3SG left
'George left singing.'

Gabriela Alboiu argues that the null subject of the Romanian subordinate clause, in sentence

\footnotetext{
${ }^{13}$ Dobrovie-Sorin (1994: 118).
} 
(11), is of type PRO, and can be nothing else but PRO. ${ }^{14}$ It seems clear that a certain kind of anaphoric relation exists between the subject of the main clause and that of the subordinate. Be that as it may, does sentence (11) display any IEM features? No, because sentence (11) is not the right kind of sentence: it's not as if George left but then he kept wondering whether it was he who was singing. IEM only arises under very special circumstances: it usually takes a psychological verb to engender this phenomenon, and "leave" and its Romanian counterpart "a pleca" is not the right kind of verb. So, even though sentence (11) has the right syntax, having the null subject of the subordinate clause be of type PRO does not show anything with regards to IEM or de se. Or, more precisely, it shows that PRO, in Romanian, is not really connected with IEM and/or de se.

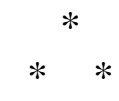

Let us take stock. The examples discussed so far are supposed to show that, in Romanian, neither IEM nor de se are connected with PRO, as they (allegedly) are in English. I chose to discuss Romanian complex sentences, which have subordinate clauses that are either infinitival or gerundive complements, because Higginbotham believed that their English counterparts provide evidence for his conjecture. There were two main findings, in this regard: first, in Romanian we have no infinitival complements of the relevant kind. In Romanian, it is the subjunctive that allows us to say the same things as the infinitive does in English. In this regard, it is noteworthy that the null subject of Romanian subjunctive subordinate clauses is not of type PRO. However, such contexts exhibit IEM features, as I established on independent grounds. So, in the case of the Romanian subjunctive, the connection between PRO and IEM is severed.

Second, I talked about the syntax of Romanian gerundive complements, inside the scope of a psychological verb, like "remember" or "imagine". It turns out that only "imagine", and not also "remember", can be used in constructions with gerundive complements, in Romanian. The subject of these subordinate clauses is an NP-trace, raised to the object of the main clause. So, there is no connection between PRO and IEM, in this type of context, either. An NP-trace is a different

\footnotetext{
${ }^{14}$ This is implied in Alboiu (2009) and confirmed via private email exchange, March 20, 2010.
} 
type of construction than a PRO structure. Thus, Higginbotham's conjecture doesn't apply here any more than it applies in the case of subjunctive complements.

Third, I considered some cases of gerundive complements that are thought to be PRO-constructions. Even if the linguists who think this are right, these context do not display any IEM features, so these contexts cannot show that there is a necessary connection between PRO and IEM, in the way that Higginbotham hypothesized.

If the arguments discussed in this section are correct, PRO cannot be said to always be the bearer of IEM, since Romanian does not have PRO-contexts, in the relevant cases, and there is no way of knowing (on syntactical grounds alone) whether the agent of an act of imagining or remembering is experiencing it in a de se manner or not.

In the next section, I investigate whether there is any other type of obligatory control - different from PRO - that can be said to be the bearer of IEM, in Romanian.

\section{Is lexical control necessarily connected with IEM?}

We have seen that, in Romanian, there is no connection between PRO and IEM: we encounter both contexts that have IEM, but the subject of the subordinate clause is not of type PRO, and contexts where PRO is present, which have no IEM features. To see whether the linguistic data from Romanian supports Higginbotham's conjecture, we should investigate whether there is anything else that works in the same way as PRO does in English. We should, thus, be looking for a pattern that always requires that the subject of the main clause is necessarily co-referential with the subject of the subordinate. This would be brought about by the main verb having obligatory control effects over the subject of the subordinate. Syntactic control of this kind, as we have seen, does not exist in Romanian. However, another type of control, namely lexical, could play the same role. If we found that, in Romanian, there are verbs whose lexical features impose obligatory control effects on the subject of the subordinate, and thus give rise to IEM features for the contexts in which they are used, Higginbotham's conjecture is right. 
In this section, I will argue that such a connection does not exist: some verbs have the required lexical features, but others don't. Interestingly, both types of verbs may be used in contexts that exhibit IEM features - so the IEM features of those contexts cannot be explained in terms of lexical obligatory control. The examples discussed in what follows should help us see this.

Some Romanian verbs impose obligatory control effects, when they are used in the main clause of a complex sentence: "a intenționa" ("to intend"), "a începe" ("to start"), "a încerca" ("to try"). Their lexical features tell us that the subject of the main clause is necessarily the same as the one of the subordinate. Sentence (12) should make this explicit (variable $x$ indicates that the subject of the subordinate is an anaphor, obligatorily co-referential with the main subject):

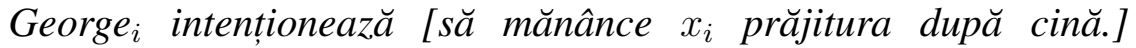
George $_{i}$ intend-3SG [să eat-3SG $x_{i}$ cake-the after dinner $]$ 'George intends to eat the cake after dinner.'

Given the lexical features of the main verb, "a intenționa" ("to intend"), sentence (13) is unacceptable:

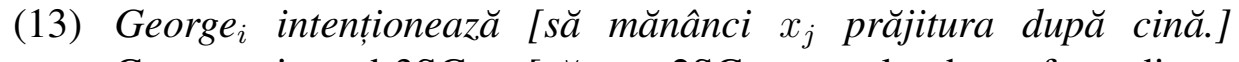
George $_{i}$ intend-3SG [s $\breve{a}$ eat-2SG $x_{j}$ cake-the after dinner $]$ 'George intends you to eat the cake after dinner.'

It would thus seem that we can obtain the required logical form, which Higginbotham's conjecture postulates to be key to understanding IEM. Even though PRO doesn't have the required role, the fact that these verbs impose obligatory control effects on the subject of the subordinate clause may indicate that we have what we need to express the same linguistic phenomenon in English and Romanian. This particular seeming is, however, problematic: there are important counterexamples to contend with. It's true that the Romanian counterpart of "intend" is a "good verb": it is a verb we would expect to use in contexts that have IEM features. There are other verbs, however, that can be used in contexts exhibiting IEM features, even though their lexical attributes do not carry with them obligatory control effects. There are many verbs that are misbehaving in this way: " $a$ vrea" ("to want"), "a-și/se imagina" ("to imagine”), "a-și aminti” ("to remember”), to name only a few. Let us look at the following two sentences: 
George $_{i}$ vrea [să mănânce pro ${ }_{i}$ prăjitura după cină.]

George $_{i}$ want-3SG [să eat-3SG pro $_{i}$ cake-the after dinner]

'George wants to eat the cake after dinner.'

(15)

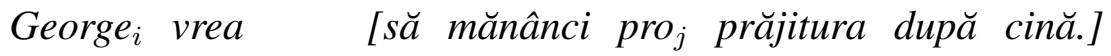

George $_{i}$ want-3SG [să eat-2SG pro $_{j}$ cake-the after dinner]

'George wants you to eat the cake after dinner.'

Both (14) and (15) are grammatical and acceptable, in Romanian. The fact that (15) is acceptable indicates that "a vrea" ("to want") is significantly different from "a intenționa" ("to intend"), since the latter verb could not be used in constructions like sentence (15), as shown by sentence (13). The lexical features of the latter verb impose obligatory control, but those of the former do not. Now, the problem is that sentence (14), just like sentence (12), does have IEM. But the IEM features of sentence (14) can't be explained in terms of lexical obligatory control. This should indicate that lexical obligatory control, in Romanian, is no more useful to us than syntactic obligatory control was.

These examples indicate that IEM is not connected with lexical obligatory control in Romanian. One has to know what those sentences mean, in order for one to understand whether a sentence has IEM or is a de se report or not. The "misbehaving" verbs allow for the required theta-roles to be filled in such a way that IEM is obtained. To my mind, this shows that those verbs have that kind of theta-roles because they are needed to be used in IEM contexts, and not that their being used in IEM contexts is explained by their having the necessary theta-roles. In other words, while Higginbotham thinks that the language is a good guide to understanding IEM and the peculiar psychological states that display the IEM phenomenon, I think the opposite is true: psychology is a good indication of why language allows for certain things to be expressed the way they are. It is precisely because the psychological states in question are reflexive that the relevant contexts (i.e. those about the states in question) exhibit IEM features, and not the other way around. 


\section{Concluding remarks}

In this paper, I argued that it is not possible to know whether a certain linguistic context, containing a reference to the first person, is immune to error through misidentification, just by looking at its syntactic form alone. This goes against Higginbotham's claim that the understood subject, PRO, in English, is always the bearer of IEM features and indicates a truly de se context. In order to show that this thesis is incorrect I analyzed Romanian syntax, focusing on the grammar of the sentences that are used to translate the English examples used by Higginbotham. I found that in Romanian, one can have contexts that are IEM, but their syntax doesn't contain PRO; or, one can have contexts whose syntax (probably) includes PRO, but they do not display any IEM features. Moreover, I found that there may be a syntactical form that is a trigger of de se, in Romanian, namely Romanian subjunctive I, but even here further qualifications are needed, in order to know that such a context has IEM. Linguistic form alone doesn't indicate when a sentence has IEM or a certain report is de se. One needs to know what the verbs under scrutiny mean, in order to get the needed information about the subjects of the different clauses.

Since both the phenomenon of IEM and that of de se can be found in Romanian, I argue that explaining them cannot start with an investigation of language, since, as we have seen, linguistic form may be misleading. It may be the case that certain psychological verbs and/or states are found to have IEM, because of the particular mode of (re)presenation they are characterized by. So, a report of someone remembering something will be said to have IEM, because that report is made in the memory mode, and all reports made in the memory mode have IEM, or something along these lines. It is true that this observation, which is adapted from Recanati, doesn't explain much; it's more of a factual observation. However, it is a way of emphasizing what IEM and de se states have in common: they are all reflexive states, as Higginbotham calls them, or they share a certain type of mode that injects the needed reflexivity, as Recanati argues. To better understand these characteristics, one should do well to look at the workings of the mind, rather than of language(s). 


\section{References}

Alboiu, G. (2009). Null Expletives and Case: The View from Romance. In P. Masullo, E. O’Rourke, \& C. Huang (Eds.), Romance Linguistics 2007 (pp. 1-18). Amsterdam: John Benjamins.

Alboiu, G. \& Motapanyane, V. (2000). The Generative Approach to Romanian Grammar: An Overview. In V. Motapanyane (Ed.), Comparative Studies in Romanian Syntax (pp. 1-48). Amsterdam: Elsevier Press.

Capone, A. (2016). The Pragmatics of Indirect Reports. Socio-philosophical Considerations. Springer International Publishing.

Chierchia, G. (1989). Anaphors and attitudes de se. In R. Bartsch, J. van Benthem, \& van Emde Boas (Eds.), Language in Context. Dordrecht: Foris.

Cumming, S. \& Sharvit, Y. (2016). Faithfulness and De Se. In A. Capone, F. Kiefer, \& F. Lo Piparo (Eds.), Indirect Reports and Pragmatics (pp. 489-506). Springer International Publishing.

Chomsky, N. (1981). Lectures on Government and Binding. Dordrecht: Foris

Dobrovie-Sorin, C. (1994). The Syntax of Romanian: Comparative Studies in Romance. New York: Mouton de Gruyter.

Folescu, M. \& Higginbotham, J. (2012). Two Takes on the De Se. In S. Prosser, F. Recanati (Eds.), Immunity to Error Through Misidentification: New Essays (pp. 46-62). Cambridge: Cambridge University Press.

Higginbotham, J. (2010). On Words and Thoughts about Oneself. In F. Recanati, I. Stoianovic, \& N. Villanueva (Eds.) Context-dependence, Perspective, and Relativity (pp. 253-282). Berlin: Mouton de Gruyter.

- (2003). Remembering, Imagining, and the First Person. In A. Barber (Ed.), Epistemology of Language (pp. 496-533). Oxford: Oxford University Press.

Hornstein, N. (1999). Movement and Control. Linguistic Inquiry, 30(1), 69-96.

Peacocke, C. (2008). Truly Understood. Oxford: Oxford University Press.

Recanati, F. (2007). Perspectival Thought: A Plea for Moderate Relativism. Oxford: Oxford University Press.

Shoemaker, S. (1968). Self-Reference and Self-Awareness. Journal of Philosophy, 65(19), 555567.

Wittgenstein, L. (1958). The Blue and Brown Books. Oxford: Blackwell. 